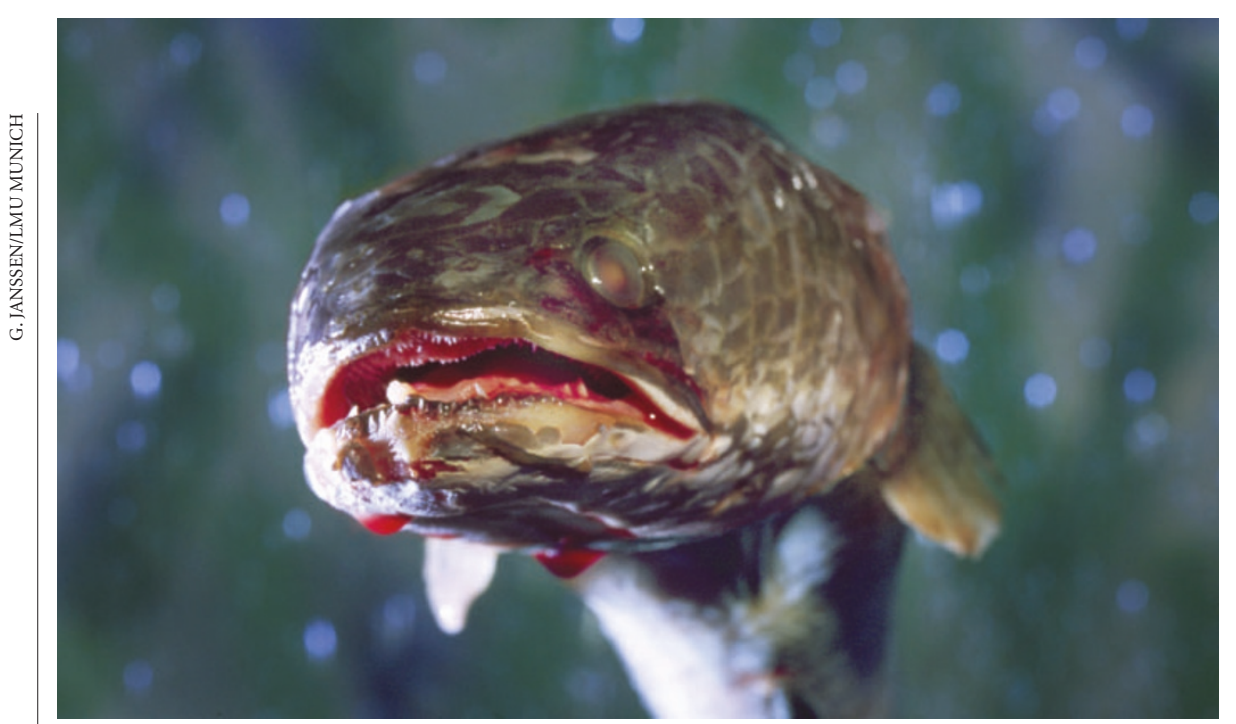

Off the hook: snakeheads caused alarm in Maryland in 2002, but have now been put to good use.

\title{
Fishy predator gets its teeth into ancient climate history
}

\section{Quirin Schiermeier, Munich}

In the horror film Snakehead Terror, released last month by Sci-Fi Pictures, killer fish mutate to monstrous proportions, devouring everything in reach. And some escaped northern snakeheads (Channa argus) did indeed cause a panic two years ago when they were caught by fishermen in Maryland. But German scientists believe these amphibious fish may serve a more benign purpose - as markers for past climate change.

Snakeheads (Channidae) are a group of predatory freshwater fish native to Africa and southern Asia. They can live out of water for extended periods, jump up to four metres high and cover large distances on land hence the problem in Maryland, where they had apparently been released after being bought in a New York live fish market for a home aquarium. Fears of their uncontrolled spread even reached the late-night talk shows.

But a study by Madelaine Böhme, a palaeontologist at the University of Munich, to be published in next month's issue of Geology, could help salvage the snakehead's public image. She says that the fish's extensive migratory history could tell researchers about the climate of the past.

Böhme searched hundreds of fossil freshwater fish deposits, in collections from Beijing to Montpellier, for the presence or absence of snakeheads. She then used the information to reconstruct the species' migration and extinction history during the Miocene period, from 24 million to 5 million years ago. This provides a good indicator of summer precipitation, because the fish's present-day distribution suggests that snakeheads are limited to climates with at least one month of rainfall of 150 millimetres and a mean temperature of $20^{\circ} \mathrm{C}$.

"What we have here is a major new proxy for Miocene precipitation and humidity information that is otherwise extremely difficult to get," says William Hay, a palaeoclimatologist at the University of Colorado in Boulder. That information should prove useful in refining climate models, by comparing their predictions with the actual climate record, he says.

During the past 20 million years, snakeheads have twice migrated from their Himalayan origins to subtropical and temperate regions in Africa and Eurasia, Böhme reports (M. Böhme Geology 32, 393-396;2004).

Böhme's study suggests that the most extended migration events - 17.5 million years ago, and between 8 million and 4 million years ago - must have been linked with changes in atmospheric circulation in the Northern Hemisphere, which led to increased air humidity and summer precipitation in regions that were formerly dry in summer.

"The presence of snakehead fossils in central European deposits indicates that in a much warmer climate the region had come under the influence of moist northern trade winds," says Böhme. This, she adds, is likely to have been caused by a northward shift of the 'meteorological equator' - a weather trough that normally sits just north of the Equator.

Although this is the first time that the migration of fish has been used as an indicator for palaeoclimate, the effect of climate change on population dynamics is already a hot issue. Research carried out on caribou and musk oxen on opposite coasts of Greenland, for example, revealed that animal populations of different species may respond synchronously to global climate change over large regions (E. Post and M. C. Forchhammer Nature 420, 168-171;2002).

\section{Money changes hands in key bank transaction}

Eva Schillinger, Munich

One of the most secure methods of quantum cryptography has been used commercially - for a single transaction, at least. On 21 April, Austrian scientists used the technique to transfer a $€ 3,000$ (US\$3,500) donation to their lab.

Quantum cryptography uses the odd properties of quantum particles to create secure keys for encoding and decoding messages. The very act of observing these particles changes their nature, making it easy to detect any eavesdroppers.

Anton Zeilinger, a quantum physicist at the University of Vienna, and his team carried out their bank transaction by applying a particularly secure technique that uses a pair of entangled photons to create the key.

The properties of these photons depend on each other, even when they are separated by long distances. After entangling the pair, one is sent to the recipient. Upon arrival, both photons are measured by their respective owners. This act of measurement determines the state of the photons, and thus the state of the key.

Before measurement, neither photon carries any useful information that could be stolen by a snoop. "This makes data transmission more secure," says Zeilinger.

In last week's trial, the entangled photons were created in a branch of the Bank of Austria in Vienna. One was sent to the city hall through a 1,450-metrelong fibreglass cable. The transfer took 90 seconds to complete; the money was then donated to Zeilinger's lab.

Some companies already sell quantum-cryptography hardware. But these systems use single photons to communicate the key (see Nature 418, 270-272; 2002). In such systems, there is a small possibility that the key could be intercepted without anyone noticing. Zeilinger's photon pairs eliminate this potential flaw, he says.

It has taken Zeilinger's group two years to create a commercial prototype of entangled-photon cryptography, with the help of the Austrian company ARC Seibersdorf Research. So far, the system works well enough for a single test, but it is not quite ready for sale. "We hope that all problems of implementation will be solved within three years," says Zeilinger. 